\title{
Micro Gasturbine Integrated Design. Part 1: Thermodynamic Cycle, Combustor, Recuperator and Bearings
}

\author{
Dario Barsi, Tiziano Garbarino, Andrea Perrone*, Luca Ratto, Gianluca Ricci, Fabrizio Stefani, Pietro Zunino \\ DIME - University of Genova, Via Montallegro 1, 16145, Genova, Italy
}

\begin{abstract}
In the last years micro gasturbines for cogeneration power plants have been proved to be a promising technical solution for the distributed production of electricity and heat. In order to enhance the machine efficiency and make it competitive with internal combustion engines, it is necessary to improve the efficiency of each component of the GT: in the first part of the paper the focus will be put on the combustor, the recuperator and the bearings. Combustor and bearings are cutting edge technology and for them a brief description of the design procedure has been reported. The recuperator plays a key role in the cycle efficiency, since the reduction of the pinch point temperature difference can strongly enhance the overall efficiency.
\end{abstract}

Keywords: Cogeneration, Bearings, Combustor, Recuperator

\section{Introduction}

The distributed generation of energy is becoming more and more interesting from the economical and environmental point of view for the possibility of installing, nearby the site of use, small generation units that can provide at the same time electric and thermal energy that can be used directly for civil heating, cooling or for industrial processes. This is called microcogeneration. In a few words, three fundamental characteristics of the microcogeneration are:

- long, heavy, expensive, environmentally impacting high voltage electric grid are avoided;

- efficient use of fuel with more than $30 \%$ (state of the art) electric energy plus more than $45 \%$ of thermal energy from the $100 \%$ fuel chemical energy. Large global energy generated for $1 \mathrm{~kg}$ of $\mathrm{CO}_{2}$ produced;

- location of the small generation units in proximity of the civil, rural or industrial settlements requires low pollution combustion. Small GT units with gaseous fuel premixed combustion guarantee low emissions.
In the last years microgas turbines used in cogeneration power plants have been proved to be a promising technical solution for distributed combined production of electricity and heat, especially due to their low emissions and fuel flexibility [1]. In fact the main characteristics of this kind of power plants are:

- Large global efficiency $\left(\eta_{G}>75 \%\right)$

- Very low emissions $\left(N O_{x}<15 p p m, C O<15 p p m\right)$

- $\quad$ Long useful life (>60.000 hours)

- Simple installation

- Simple maintenance

- Simple operation

- Simple and remote control

- High reliability

An effort should be made to improve performance of the microturbine in order to enhance cycle efficiency, taking it closer to other technologies widely employed in this field. In particular, components efficiency heavily affects

${ }^{*}$ Corresponding author

Email: andrea.perrone@edu.unige.it

(C) 2016 International Association for Sharing Knowledge and Sustainability

DOI: $10.5383 /$ ijtee. 11.01 .002 
plant performance and aerodynamic design of novel geometries has to consider mechanical constraints in order to pursue this target without compromising machine integrity [2], [3].

\section{Thermodynamic Cycle}

The concept design of the micro gas turbine starts from the analysis of a regenerative Brayton cycle (Figure 1) suitable for the specific application.

In the present paper, a microturbine for cogenerative application with $100 \mathrm{~kW}$ of electric power output has been considered. Relating to the fluid-dynamic parameters such as components efficiencies, total pressure losses, heat transfer and insulation coefficients, several assumptions have to be considered.Figure 1 Regenerative Brayton Cycle

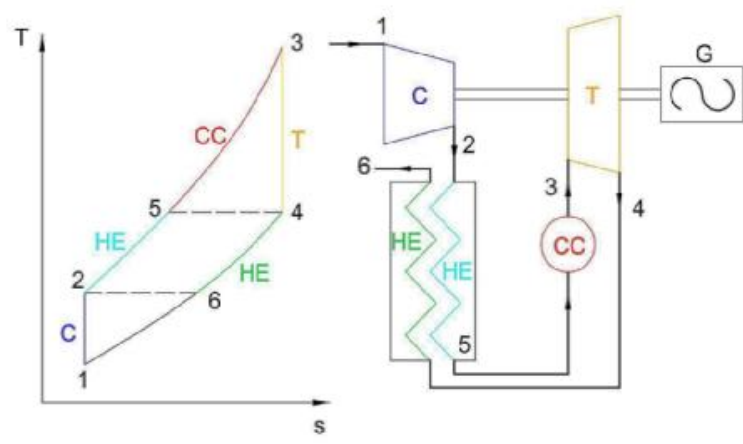

These parameters have been assumed from literature, components datasheets and other scientific papers and are summarized in the Table 1 . These values represent the state of the art of a $100 \mathrm{~kW}$ micro gas turbine technology available on the market. The calculations have been carried out through the open source in-house developed code GT cycle Error! Reference source not found..

Table 1: Main Cycle Parameters for 100kW MicroGasturbine

\begin{tabular}{ll}
\hline Parameters & Value \\
\hline Compressor efficiency & $80 \%$ \\
Turbine efficiency & $86 \%$ \\
Recuperator effectiveness & $84 \%$ \\
Pinch point temperature & $70{ }^{\circ} \mathrm{C}$ \\
difference & \\
Combustor efficiency & $95 \%$ \\
Generator efficiency & $96 \%$ \\
Mechanical efficiency & $99 \%$ \\
Compressor pressure ratio & 4.4 \\
TIT & $950^{\circ} \mathrm{C}$ \\
Recuperator hot pressure losses & $100 \mathrm{mbar}$ \\
Recuperator cold pressure losses & $150 \mathrm{mbar}$ \\
Combustor pressure losses & $175 \mathrm{mbar}$ \\
Intake pressure losses & $10 \mathrm{mbar}$ \\
Exhaust pressure losses & $10 \mathrm{mbar}$ \\
Cycle Efficiency & $30 \%$ \\
\hline
\end{tabular}

The considered cycle has a maximum turbine inlet temperature of $T I T=950^{\circ} \mathrm{C}$. It is due to the maximum thermal load that can be applied to nickel based super alloys, since the blades are not cooled. For this TIT a totalto-total pressure ratio of the cycle $\beta_{\mathrm{t}-\mathrm{t} \text { cycle }}=4.4$ has been found to maximize the Brayton-Joule thermodynamic efficiency. It results in a total-to-total pressure ratio of the turbine of $\beta_{t-t}$ turb $=3.7$, once the pressure drop in the combustion chamber as well as in the exhaust duct are considered. Finally, in order to obtain the desired net output power of the system, $\mathrm{P}=100 \mathrm{~kW}_{\mathrm{e}}$, a target mass flow rate of about $\dot{m}=0.75 \mathrm{~kg} / \mathrm{s}$ has been considered.

As reported in the previous table, the efficiency of the thermodynamic cycle is $30 \%$. This value can be improved increasing the TIT over the current technological limit of $950^{\circ} \mathrm{C}$ due to the use of nickel super alloys. In recent years a great deal of effort has been devoted to research and development of innovative ceramic materials for the manufacturing of turbine impeller in order to increase turbine inlet temperature and, consequently, to enhance the global efficiency.

To overcome this technological limit, advanced heat transfer techniques are employed both in industrial heavy duty gas turbines and aeroengines. However, there are very few applications of cooled radial impellers, mainly due to manufacturing constraints. Moreover, a detailed thermodynamic analysis has been carried out in order to highlight pro and cons of blade cooling with simple cycle and with recuperated cycle. Results are shown in Figure 2 and the data sets have been obtained varying maximum cycle pressure and TIT .

Figure 2 shows a comparison of cooled and uncooled GT configurations, both for simple and recuperated cycle, considering a fixed amount of coolant flow. The diagrams display that in both cases, as obvious, the cooled configuration reaches a lower global efficiency. However, this efficiency reduction is more evident for the recuperated cycle, where it is, on average, greater than the other case and it tends to increase approaching lower pressure ratios, typical of micro GT applications. These results show that for a recuperated gas turbine the cooling technology provide less significant advantages than those obtained in simple cycle configurations.

\section{A thorough investigation has been carried out in order to highlight the influence of each micro GT component efficiency variation on the overall cycle efficiency. Figure 3 shows two levels of main components optimization and values are summarized in}

Table 2. 

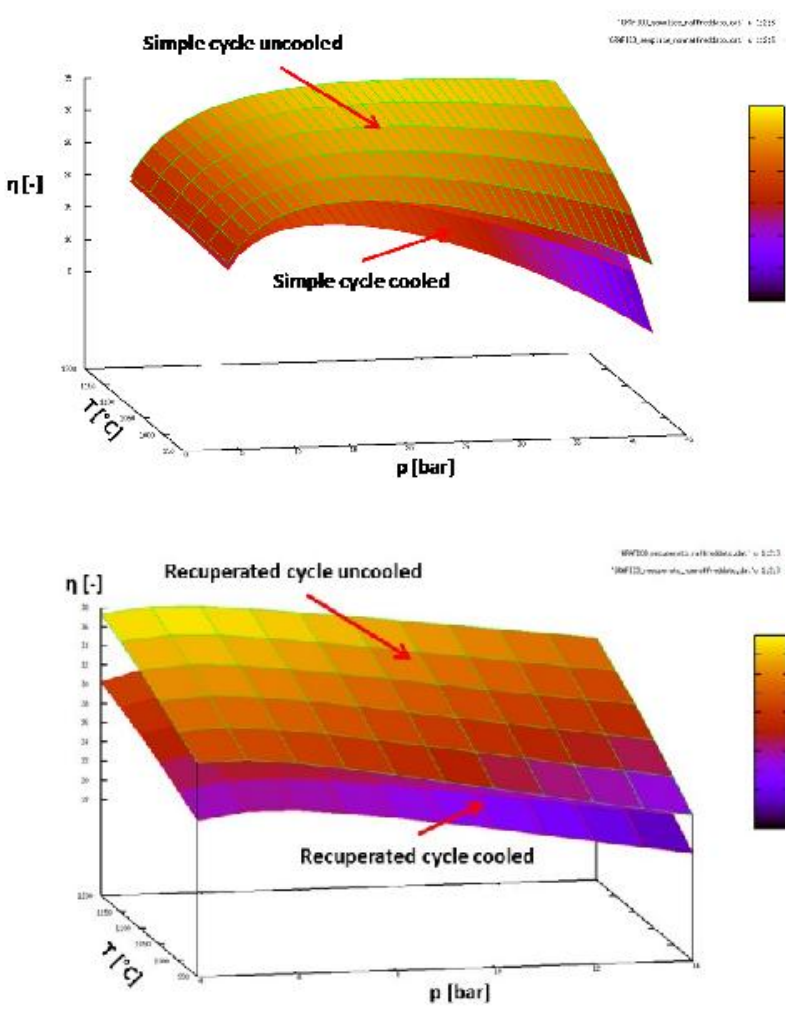

Figure 2 - Efficiency Analysis for Cooled and Uncooled Simple and Regenerated Cycle

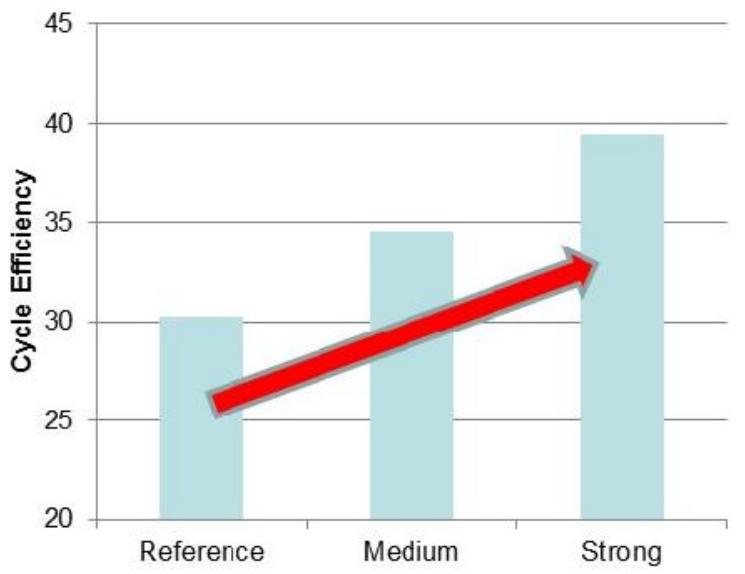

Figure 3: Effect of Components Optimization on Cycle Efficiency

Considering compressor and turbine, results have shown that the same component efficiency increase leads to different overall cycle efficiency. This is the consequence of the lower specific energy exchange of the compressor with respect to the turbine, with a greater influence of the latter.
Table 2: Assumed Efficiency and Effectiveness of Components for Two Levels of Optimization

\begin{tabular}{|l|c|c|c|}
\hline & Reference & Medium & Strong \\
\hline Compressor & $80 \%$ & $82 \%$ & $84 \%$ \\
\hline Turbine & $86 \%$ & $88 \%$ & $90 \%$ \\
\hline Recuperator & $84 \%$ & $89 \%$ & $94 \%$ \\
\hline
\end{tabular}

The recuperator effectiveness strongly affects the machine efficiency. Recuperator design has to be a compromise between performance improvement, size and weight constraints.

Finally, a strong optimization of the main components, preserving the same TIT, can lead to efficiency values up to $38 \%$, much higher than the state of the art.

\section{Combustion Chamber}

The combustion chamber design represents a key point in order to achieve the desired overall performance of the entire micro-gas turbines cogenerative power plant. In order to be adequate to be employed in micro cogenerative power plants, the combustor has to satisfy some fundamental requirements:

- large combustion efficiency and low pollutant emissions;

- combustion stability and reliable ignition;

- low total pressure losses;

- uniform outlet temperature distribution.

To achieve the first requirement it is necessary to obtain a complete combustion and exhaust gas free as possible from unburnt fuel $U H C \mathrm{UHC}$, carbon monoxide $C O$, nitric oxide $\mathrm{NO}_{\mathrm{X}}$ and smoke. Low efficiency, $C O \mathrm{CO}$ and $\mathrm{HC}$ are mainly the result of inadequate residence time in the primary zone of the combustor, while thermal $N O_{x}$ formation is controlled by flame temperature and increases with residence time. Little $N O_{x}$ is formed at temperature below around $1850 \mathrm{~K}$.

Lean premixed combustion significantly decreases flame temperatures and consequently reduces $N O_{x}$ formation. Moreover for lean premixed combustors $N O_{x}$ formation is independent of residence time (since it is a prompt mechanism) and, as a consequence, strong reduction of pollutant emissions is achieved with LP combustors.

The level of premixing plays a critical role in the performance of the combustor; some considerations have to be done:

- if the premixing duct is too long, the mixture stays in there for a time larger than characteristic ignition time (physical time, for evaporation and mixing + chemical time) with risk of auto ignition and thus combustion in the premixing duct; 
- whenever the flame speed exceeds the approach flow velocity, flashback in the premixing ducts can occur;

- if pressure and heat oscillations are phased they may be auto excited and bring to combustor failure due to thermo-acoustical instabilities.

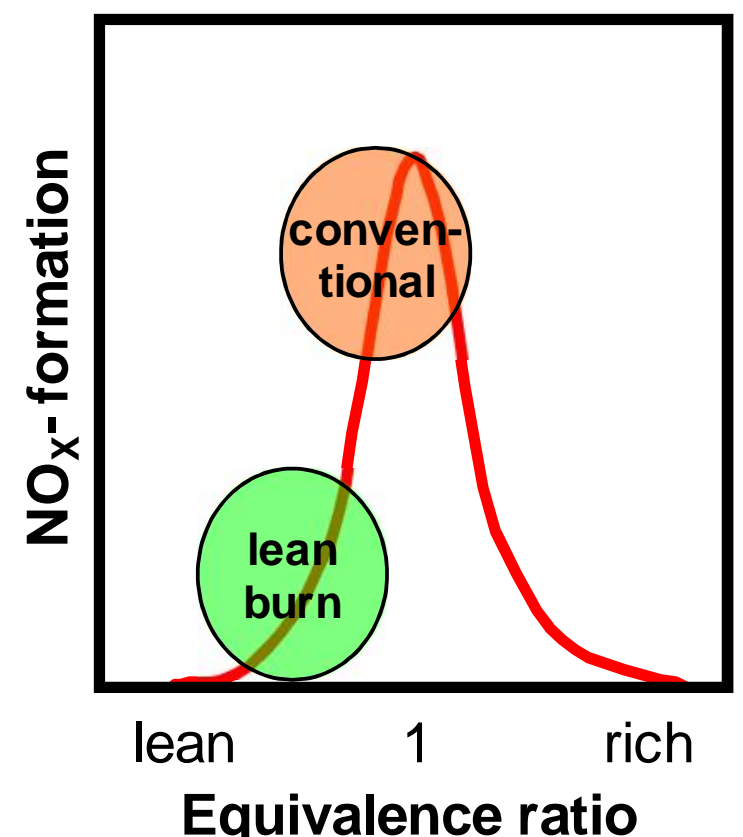

Figure 4 - Conventional and Lean Burn Combustion $N O_{x}$ Formation

For what concerns the flame stability and reliability of ignition, the combustion must be maintained over a wide range of operating conditions. Combustion must be initiated and sustained in highly turbulent flows that generally have speed greater than the flame speed ( $S_{L}=1.3 \mathrm{~m} / \mathrm{s}$ for methane stoichiometric mixture at $T=900 K$ and $p=4.5$ bar ). A solution can be found by creating a recirculation zone in the primary zone of the liner by means of swirler injectors, where flame speed is enhanced by a high level of turbulence and the recirculating hot products provide heating of the incoming flow at the ignition temperature.

\section{A. Preliminary Design Procedure}

The first step consists of a combustor preliminary design procedure able to define the fundamental overall conditions and geometrical parameters of the combustor. For the specific application a silo type combustion chamber has been adopted, mainly for simpler maintenance and manufacturing.

From the optimization process of the thermodynamic efficiency of the cycle it is possible to evaluate the air mass flow rate, $\dot{m}_{A}$, the inlet thermodynamic pressure $p$, and the temperature values $T_{1}, T_{2}$. Starting from these values it is possible to evaluate the fuel mass flow rate, $\dot{m}_{F}$. A lean premixed burn concept is implemented to obtain low pollutant emissions, with an equivalence ratio of $f=0.4-0.45$. Thus it is possible to calculate the mass flow rate in primary zone, $\dot{m}_{A_{p}}$. The remaining mass flow rate $\left(\dot{m}_{A}-\dot{m}_{A p}\right)$ has to be properly subdivided between cooling $\dot{m}_{A_{c}}$ and dilution $\dot{m}_{A d}$ mass flow rates. This subdivision has to take into account from one side that the amount of air needed for cooling depends on the maximum temperature in the primary zone, cooling technology and liner material, and from the other side that the dilution air has to enable uniform exit temperature distribution.

\section{B. Primary Zone Analysis}

In order to obtain a low total pressure loss and at the same time a high flame stability, the mean velocity of the flow within the primary zone is assumed to be of about $15-20 \mathrm{~m} / \mathrm{s}$. From this assumption it is possible to evaluate the liner diameter. In addition, the primary zone length has to enable the complete combustion of fuel for each operating condition. As a consequence, by imposing that the primary zone residence time has to be higher than the burning time, it is possible to obtain the primary zone length.

Furthermore, in order to allow flame stability by means of an adequate recirculation zone, the injectors must provide a proper swirl number, defined as:

$$
N_{s w}=\frac{\int \rho v_{a} v_{t} r^{2} d r}{R \int \rho v^{2}{ }_{a} r d r}
$$

\section{Cooling and Dilution Zone}

Rows of cooling holes generate jets through the liner to keep the temperature lower than the maximum allowable value, while dilution holes provide the desired exit mean temperature and temperature uniform distribution. Hole number, diameters and disposition must be evaluated and optimized. A first guess solution, however, can be found by applying the simplified relation suggested by [4].

\section{Injector}

A lean premixed flame with small diffusion flame in order to provide flame stability at part-load conditions can be chosen. Air and fuel for lean premixed flame are injected through the external swirler, while air for pilot diffusion flame is injected through the internal swirler. In order to obtain a higher flame stability corotating swirlers are employed. By imposing an overall swirl number $N_{s w}>0.5$ a swirler exit flow angle higher than 30 degree 
is obtained. In conclusion the overall requirements of the injection system are:

- turbulence intensity higher than $15 \%$ in order to enhance the mixing process;

- residence time lower than autoignition time to avoid ignition in the premixing duct;

- flow velocity in premixing duct higher than turbulent flame speed $S_{t}$;

- $\quad$ avoiding recirculation zones in the premixing duct.

By following the assumptions listed before, a first guess geometry for the can combustor can be obtained. In Figure 5 , an overall view of the preliminary geometry and some peculiar details are sketched.

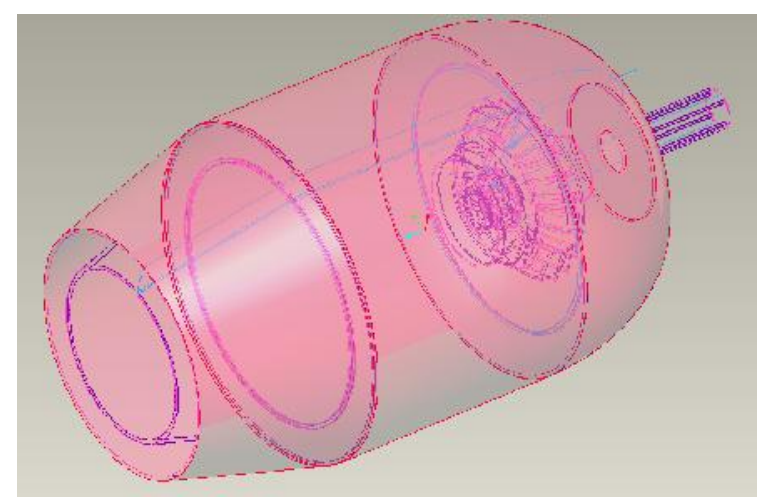

Figure 5 - Combustion Chamber Preliminary Design

\section{Recuperator}

\section{A. Recuperator configuration choice}

The recuperator analyzed in this application is a primary surface type, due to its favorable properties of effectiveness, weight and reliability [6]. The exchange surfaces are modeled as Cross Wavy surface (reported in Figure 6), since they are successfully employed in state of the art recuperated microturbines[7] (see Figure 7).

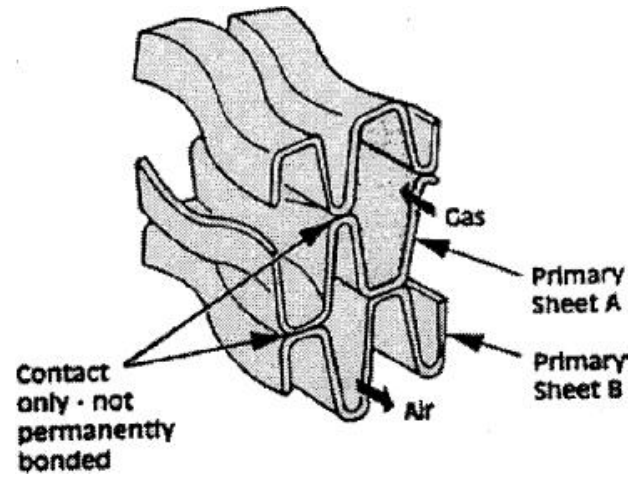

Figure 6: Cross Wavy Surface Scheme [9]
The Cross Wavy pattern presents two different cross sections, the larger ones allow the passage of the hot gas, while the compressed air passes through the smaller channels. Each duct is made of two corrugated metal sheets welded at the edge. The welded construction, compared to the brazed one (used in plate-fin recuperators), is cheaper and more reliable and it is one of the strength of the primary surface recuperators. The corrugated metal sheets are wavy (out of phase of $180^{\circ}$ between them) in the main flow direction. This waviness create secondary flow structures: this structure disturbs the near wall boundary layer and so improves the heat transfer [9].

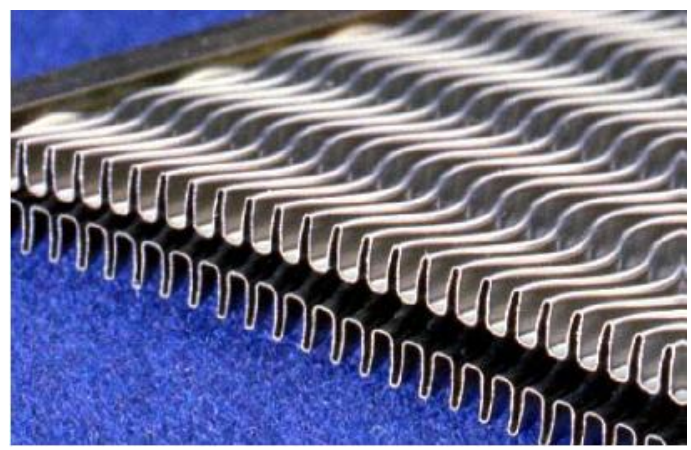

Figure 7: Particular of the Cross Wavy Recuperator Mounted on the Capstone Microturbines [8]

The specific surface geometry adopted in this work is sketched in Figure 8 and Figure 9. The ducts have trapezoidal cross section rounded at the top of the channel, while the waviness is made of straight lines connected to part of circles. This surfaces modelling follows that explained in [10] with the aim of create a geometry similar to that reported in Figure 6 and Figure 10.

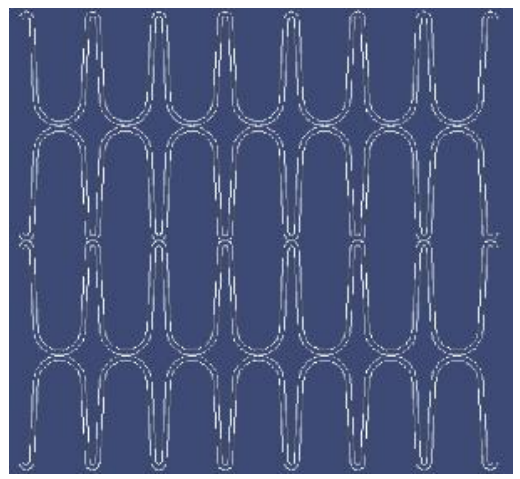

Figure 8: Cross Section of the Exchange Surfaces Studied 


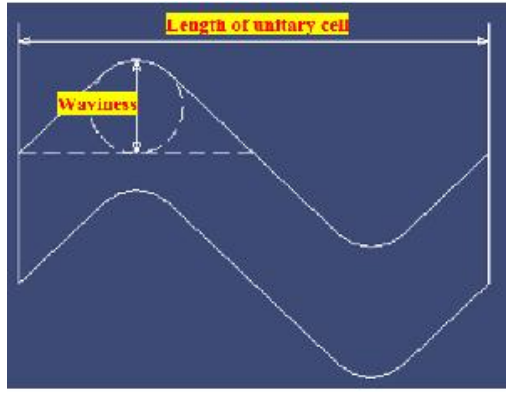

Figure 9: Waviness of the Cross Wavy Ducts Studied

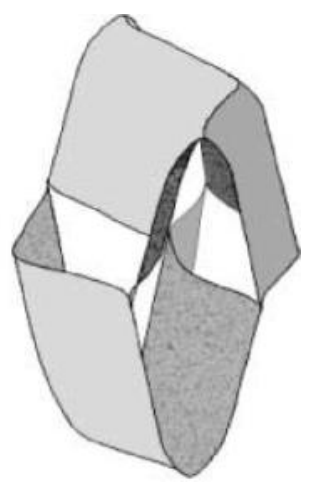

Figure 10: Model of a Single Cross Wavy Duct [10]

In [6], the geometrical data of different Cross Wavy patterns are reported. Each pattern has the same cross section but different waviness and length of unitary cell (see Figure 9). The analyzed ducts are developed keeping the same proportion of the CW2-z5 pattern. The cited geometry is one of that studied in a CFD analysis conducted in [10]: the study provided data later arranged into simple correlations for the Nusselt number and the Fanning friction factor depending on the Reynolds number [9], [6]. The correlations give the results within the $10 \%$ of the original data [9] (that of the numerical simulation) and are written in the following form:

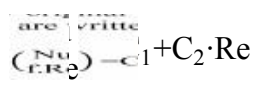

where the constants are different for each pattern. For the selected geometry, $\mathrm{C}_{1}$ and $\mathrm{C}_{2}$ are reported in Table 3.

Table 3: Coefficient of the Correlations in Eq. (2)

\begin{tabular}{|c|c|c|}
\hline Constant & $\mathrm{Nu}$ & $\mathrm{f} \cdot \mathrm{Re}$ \\
\hline $\mathrm{C}_{1}$ & 1,0441 & 35,1707 \\
\hline $\mathrm{C}_{2}$ & 0,01570 & 0,1168 \\
\hline
\end{tabular}

The recuperator is made up of conventional 347 stainless steel, which is the material usually adopted when the maximum metal temperature doesn't exceed the value of $675^{\circ} \mathrm{C}[7]$.

Furthermore, the target pinch point temperature difference has been set equal to $30^{\circ} \mathrm{C}$, in order to improve the recuperator effectiveness.

\section{B. Recuperator Design Calculations}

Once the configuration, the geometry and the material have been defined, it is necessary to calculate the dimensions of the component. Theprocedure, described in [9], has beenproperly modified in order to calculate the channel characteristics by using a parametric model. The calculation scheme requires the knowledge of two kind of information: the properties of the flows entering the recuperator (and therefore the thermodynamic cycle of the microturbine) and the geometry of the air cell (in order to scale it, if necessary). The latter is already defined in the previous paragraph, while the former requires a specific code for the calculation of the regenerative cycle performance.

The cycle calculation has been performed through GT cycle, coupled with the already cited dimensioning scheme [9] used for the recuperator design. The code requires the knowledge of pressure losses for both the recuperator sides and, for this reason, a first guess pressure losses value is assumed and then iteratively updated until convergence. A series of MATLAB functions enables to launch and manage the design tool.

The resulting dimensions of the ducts are different from those studied in [10], in order to match the value of the imposed Reynolds number. However, the proportions are kept, so it is possible to use the same correlations. The thickness of the metallic wall is the same for each calculation and is equal to $0,1 \mathrm{~mm}$ [6]. Different hydraulic diameters of the channel imply different compactness of the recuperator. The compactness is the ratio between exchange surface and volume of the heat exchanger and it is inversely proportional to the diameter of the ducts. Therefore, the compactness of the component is varied depending on the hydraulic diameter resulting from the chosen value of Reynolds number.

\section{Results and Discussion}

The iterative and parametric calculations led to a large number of different recuperator configurations. However, a lot of them present unsuitable characteristics and are discarded. The "filter" applied on the results is on the recuperator mass, volume, length, inlet gas temperature and channel dimension values.

Inlet gas temperature is limited to $675{ }^{\circ} \mathrm{C}$, in order to avoidthe employment of a more resistant and expensive material than SS347.

Regarding the channel dimensions, they are lower limited because of the strength limitation of the material. In fact, 
thin metallic foils may crack when folded with a very short length of unitary cell [9]. For this reason, all the solutions with single duct smaller than that studied in [10]have been discarded.

The limitations on the overall dimensions of the recuperator have been set due to compactness reasons. Therefore the maximum recuperator mass, the matrix volume and the matrix length have been set to $250 \mathrm{~kg}, 1$ $\mathrm{m}^{3}$ and $1 \mathrm{~m}$ respectively.

By considering all the listed assumptions and constraints, the best design solution presents a Reynolds number of 500 and a gas side velocity of $19 \mathrm{~m} / \mathrm{s}$. The other parameters and the geometrical details are reported in Table 4 . The resulting heat exchanger has a very compact design, near to the value reported in[6]. This means that the channels are very small, so the pressure losses are higher than the first guess solution ones. The overall weight takes into account additional auxiliary components (e.g. manifold, casing etc.) by means of an increase in weight of about $10 \%$. Volume and length are referred to the recuperator matrix only, so they don't include other elements.

Table 4: Recuperator Main Characteristics

\begin{tabular}{ll}
\hline Parameters & Value \\
\hline Recuperator mass & $117 \mathrm{~kg}$ \\
Recuperator front section & $0.136 \mathrm{~m}^{2}$ \\
Recuperator matrix length & $0.31 \mathrm{~m}$ \\
Recuperator matrix volume & $0.042 \mathrm{~m}^{3}$ \\
Exchange surface & $50.7 \mathrm{~m}^{2}$ \\
Compactness & $1214 \mathrm{~m}^{2} / \mathrm{m}^{3}$ \\
Pressure loss (air side) & $260 \mathrm{mbar}$ \\
Pressure loss (gas side) & $121 \mathrm{mbar}$ \\
Hydraulic diameter (air side) & $0.83 \mathrm{~mm}$ \\
Hydraulic diameter (gas side) & $1.77 \mathrm{~mm}$ \\
Length of unitary cell & 5.81 \\
Waviness & 1.16 \\
Total cross section area (air side) & $0.036 \mathrm{~m}^{2}$ \\
Total cross section area (gas side) & $0.076 \mathrm{~m}^{2}$ \\
Metal volume & $0.013 \mathrm{~m}^{3}$ \\
\hline
\end{tabular}

By employing the recuperator above described and keeping the pinch point temperature difference, compressor and turbine efficiency of $30^{\circ} \mathrm{C}, 0.80$ and 0.86 respectively, the resulting overall cycle efficiency raises from $30 \%$ to $32 \%$.

\section{Bearings}

The rotor speed of the turbine has been defined by choosing the specific speed that optimizes the cycle efficiency. After the selection of the rotation speed and the evaluation of the minimum shaft diameter, the bearing speed is assessed by means of DN parameter(where D is the diameter of the shaft housing expressed in $\mathrm{mm}$ and $\mathrm{N}$ is the rotation speed expressed in rpm), as the limit comes from peripheral velocity. Since commercial microturbines work in the high speed range, the minimum DN is the most pressing constraint in bearing choice. The other driving factors characterizing the micro gas turbines bearings are the following:

- bearing load capacity: in micro gas turbines the radial load is almost constant, even in transient operations, while the axial load due to the thrust of compressor and turbine is directed towards the compressor in base load operation whilst, during the startup phase, is directed towards the turbine;

- the dynamic behavior: the shaft layout strongly affects the eigenfrequencies of the system, which can occur at a speed lower than the operating one, therefore in the startup phase the bearings should be able to damp the vibration amplitudes of the shaft;

- dynamic behavior: in turbomachines shaft layout and compliance of the bearings, i.e. their stiffness and damping, influence critical speeds and out-ofbalance response of the rotor. Bearings must provide sufficient damping to operate with vibrations of acceptable amplitude in nominal conditions and, for supercritical rotors, to overcome the critical speed without damage. In addition, for fluid film bearings, instabilities generated due to the fluid and its interaction with other parts (whirl, whip, hammering) must be avoided.

- power losses: typically, since microturbines efficiency is in the range $25-35 \%$, bearing friction losses may influence the global energetic balance and friction factor becomes an important parameter in bearing choice. Moreover, all other losses (e. g. power required to the lubricant pump, power input for magnetic bearings...) have to be considered.

\section{A. Bearing Choice Considering Operating Conditions}

Due to the high speeds of rotation and temperatures, one of the most stressed mechanical component in micro gas turbine systems are the bearings and, therefore, lubrication system plays a key role in the operation of the machine. Therefore the most advanced tribological solutions must be considered in micro turbines systems and compared with conventional ones.

Active magnetic bearings (AMBs) and passive magnetic bearings (PMBs) use electromagnets and permanent magnets, respectively. Electrodynamic bearings (EDBs) are novel, promising supports which exploit the eddy current effects that take place in a conductor rotating in a constant magnetic field to achieve levitation. Airfoil bearings support the shaft by means of a compliant, spring-loaded foil journal lining. Ceramic hybrid bearings 
use ceramic balls in place of steel ones, while all ceramic bearings include also ceramic rings.

In this work only the airfoil bearings have been considered, since they represent the most promising solution and the current state of the art in the market.

\section{B. Airfoil Bearings}

The aerodynamic load carrying capacity of foil bearings can be computed as:

$P=K(L D)\left(\frac{1000 D \pi w}{30}\right)$

where $\mathrm{L}$ is the bearing length, $\mathrm{D}$ is the journal diameter, $\mathrm{W}$ is the rotation speed and $\mathrm{K}$ is the load coefficient.

In order to characterize foil bearing behavior by means of a suitable operating map the modified Sommerfeld number has been introduced.

It takes into account the effects of the variation of dynamic viscosity from its standard condition value. The modified Sommerfeld number is defined by:

$S^{\prime}=\frac{\left(\frac{\mu}{\mu_{0}}\right) K\left(\frac{1000 D \pi \omega}{30}\right)}{\frac{W_{t}}{L D}}$

where $\mathrm{W}_{\mathrm{t}}$ is the total external load exerted on the air film by the journal and the top foil. These loads include external load, preload, thermal expansion and centrifugal forces, dynamic loads and misalignment forces.

As reliable predictive methods and clear design criteria are still not available, an empirical method to evaluate the load capacity of foil bearings has been developed by [11]. Accordingly, aerodynamic lift is directly proportional to rotational speed with a load coefficient. The proportionality constant is referred to as load coefficient K. Foil bearings are divided into three different categories. The first one (1960-1970) is characterized by uniform stiffness of the bump foil. In the second one (1970-1980), the stiffness is variable only in one direction, e.g. for a radial bearing, either in axial direction or in circumferential direction. In the third one (since the '90) the stiffness has become variable point by point, e.g. for a radial bearing, in axial, circumferential and radial direction.

The load coefficient is a useful parameter to evaluate the performance of a foil bearing, because one of its main flaws is the lack of lift, especially at low rotation speed. Therefore, the different categories of bearings are characterized by different load coefficient, e.g. K ranges between 0.1 and 0.3 for first category, between 0.3 and
0.6 for the second category, between 0.8 and roughly 1 (up to 1.4) for the third category.

According to [12], airfoil bearing operation can be mapped by using a modified Sommerfeld number S', as it can be seen in Figure 11. In the map, at a stable working point a constant specific power loss, which depends on S' value, is generated. Radial foil bearings must be designed so that they operate at high rotation speed regime (or lightly loaded regime), that is $S^{\prime}>6$. The condition, for a typical microturbine, is fully satisfied and the bearing should operate in the high rotation speed zone of the operating map. Indeed, to a first approximation, for the average microturbine S' value equal to 56 is computed by neglecting preload as well as centrifugal and thermal load, i.e. actual $\mathrm{S}^{\prime}$ is lower.

Airfoil bearings have a maximum operative $\mathrm{DN}$ ratio of $4.4 \times 10^{6} \mathrm{~mm}$. RPM, much higher than rolling elements bearings $\mathrm{DN}$ ratio $\left(2 \times 10^{6} \mathrm{~mm}\right.$. RPM for high precision angular contact ball bearing). For an airborne foil bearing, life is theoretically not limited and, as far as load carrying capacity is concerned, foil bearings outperform rolling element bearings.

The drawbacks occur in actual operating conditions, since life is limited by start and stop cycles. Moreover, the design of airfoil bearing is very demanding and the reliability has to be further verified.

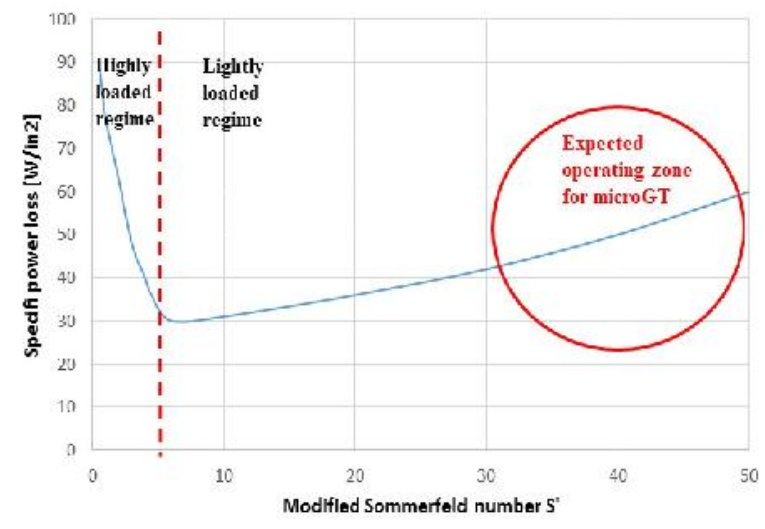

Figure 11: Operating Map of Radial Foil Bearings

\section{Conclusions}

In the first part of the paper an overall analysis of the thermodynamic cycle and the main influencing parameters have been reported. It is clearly shown that a strong efficiency optimization of the different components can lead to an overall efficiency up to $36 \%$, keeping the turbine inlet temperature at $950{ }^{\circ} \mathrm{C}$ and thus avoiding the use of ceramic materials for the turbine impeller. The preliminary design procedure has been reported for the combustor, the recuperator and the bearings, giving an insight of the integrated multidisciplinary design of the micro gasturbine. 
Finally, three main considerations can be remarked:

- turbine cooling techniques, for the current application, doesn't provide significant advantages for efficiency enhancement;

- the same efficiency increase for compressor and turbine leads to really different effects on overall efficiency, therefore it is convenient to address the design efforts on the turbine;

- the recuperator effectiveness plays a key role for the cycle efficiency, but its design has to fulfil geometrical (overall dimensions) and thermodynamic (pressure losses) constraints.

\section{Nomenclature}

\begin{tabular}{|c|c|}
\hline$A M B$ & Active Magnet Bearings \\
\hline$C_{1}, C_{2}$ & Constant values \\
\hline$D$ & Shaft diameter $[\mathrm{mm}]$ \\
\hline$E D B$ & Electro Dynamic Bearings \\
\hline$f$ & Equivalence ratio [dimensionless] \\
\hline$G T$ & Gas Turbine \\
\hline$K$ & Load coefficient \\
\hline$L$ & Bearing length $[\mathrm{mm}]$ \\
\hline$\dot{m}$ & Mass flow rate $[\mathrm{kg} / \mathrm{s}]$ \\
\hline$N$ & Rotation speed $[\mathrm{rpm}]$ \\
\hline$N_{s w}$ & Swirl number [dimensionless] \\
\hline$N u$ & Nusselt number [dimensionless] \\
\hline$T$ & Temperature $\left[{ }^{\circ} \mathrm{C}\right]$ \\
\hline$T I T$ & Turbine inlet total temperature $\left[{ }^{\circ} \mathrm{C}\right]$ \\
\hline$P$ & $\begin{array}{l}\text { Net power output }\left[k W_{e}\right] \text { or aerodynamic } \\
\text { load carrying capacity }\end{array}$ \\
\hline$p$ & Static pressure $[$ bar $]$ \\
\hline$P M B$ & Passive Magnet Bearings \\
\hline$R, r$ & Radius $[m]$ \\
\hline $\operatorname{Re}$ & Reynolds number [dimensionless $]$ \\
\hline
\end{tabular}

Flame speed $[\mathrm{m} / \mathrm{s}]$

$S^{\prime} \quad$ Sommerfeld modified number

$v \quad$ Velocity $[\mathrm{m} / \mathrm{s}]$

$W_{t} \quad$ Total external load

$w \quad$ Rotation speed $[\mathrm{m} / \mathrm{s}]$

\section{Greeks}

$\begin{array}{ll}\alpha & \text { Absolute flow angle }[\mathrm{deg}] \\ \beta & \text { Pressure ratio [dimensionless }] \\ \eta & \text { Efficiency }[\text { dimensionless }] \\ \rho & \text { Density }\left[\mathrm{kg} / \mathrm{m}^{3}\right] \\ \mu & \text { Dynamic viscosity }[\mathrm{MPa}]\end{array}$

\section{Subscripts}

$A$

$A_{d} \quad$ Dilution air

$A_{p} \quad$ Primary zone air

$a$

F

G

$L$

$t \quad$ Turbolent or tangential

$t=t \quad$ Total to total

turb Turbine

$y \quad$ Yelding

\section{References}

[1] C. S. Smugeresky, An Integrated Combined Heat and Power Distributed Energy ResourceSolution for Modular Applications. ASME Paper GT-200728294, 2007

[2] Mueller, L., Alsalihi, Z., Verstraete, T., 2013, "Multidisciplinary Optimization ofa Turbocharger Radial Turbine", Journal of Turbomachinery, Volume 135

[3] Verstraete, T., Alsalihi, Z., Van den Braembussche R., 2010, "Multidisciplinary Optimization of a Radial 
Compressor for Microgas Turbine Applications", Journal of Turbomachinery, Volume 132

[4] GTcycle, https://github.com/ampsolutions/gtcycle.

[5] Lefebvre, A.H., and Ballal, D.R. - "Gas Turbine Combustion - Alternative Fuels and Emissions", 3th edition, CRC Press, 2010.

[6] Shah R. K., 2005, Compact heat exchangers for microturbines, 5th International Conference on Enhanced, Compact and Ultra-Compact Heat Exchangers, Science Engineering and Technology.

[7] McDonald C. F., 2003, Recuperator considerations for future higher efficiency microturbines, Applied Thermal Engineering, 23(12), 1463-1487.

[8] Maziasz P. J., Pint B. A., Swindeman R. W., More K. L. and Lara-Curzio E. 2002, Advanced alloys for high temperature recuperators, DER Peer Review, 2.
[9] Utriainen E. and Sundén, B., 2002, Evaluation of the cross corrugated and some other candidate heat transfer surfaces for microturbine recuperators, Journal of Engineering for Gas Turbines and Power, 124(3), 550-560.

[10] Utriainen, E. and Sundén, B., 2002, A numerical investigation of primary surface rounded cross wavy ducts, Heat and Mass transfer, 38(7-8), 537-542.

[11] DellaCorte, C., \& Valco, M. (2000). Load Capacity Estimation of Foil Air Journal Bearings for Oil-Free Turbomachinery Applications. NASA/TM-2000209782.

[12] DellaCorte, C., Radil, K. C., Bruckner, R. J., \& Howard, S. A. (2006). A Preliminary Foil Gas Bearing Performance Map. NASA/TM-2006214343. 